استخدام نموذج ثقافة الأقران الإيجابية في خدمة الجماعة للتخفيف من حدة مشكلة قلة الوعى بالثقافة المصرية للطلاب الوافدين بجامعة الفيوم

$$
\text { إعـداد }
$$

أماني محمد البدرى عبد القادر أخصائي رعاية شباب بجامعة الفيوم 
مجلة كلية الخدمة الاجتماعية للدر اسات و البحوث الاجتماعية - جامعة الفيوك 


\section{ملخـــــ الدراســــة}

\section{أولا : ملخــص الارباســة باللغــة العربيـــة.}

\section{عنوان الدراسة:}

استخدام نموذج ثقافة الأقران الإيجابية في خدمة الجماعة للتخفيف من حدة مشكلة قلة الوعي

بالثقافة المصرية لدى الطلاب الوافدين بجامعة الفيوم.

\section{1- مثكلة الدراسة:}

لم تعد المجتمعات والثقافات منغلقة على نفسها ومن أهم مظاهر الاتصال بين التقافات المختلفة

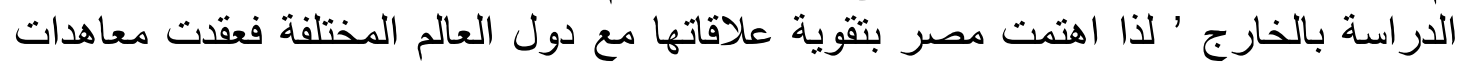

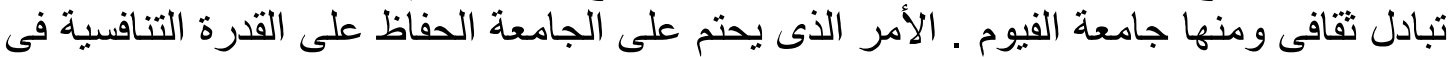
جذب الطلاب الوافدين والتكيف مع تعدد الثقافات داخل الحياة الجامعية وتلبية احتياجاتهم

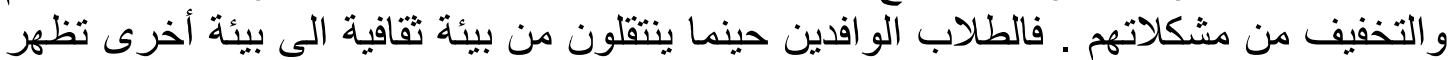

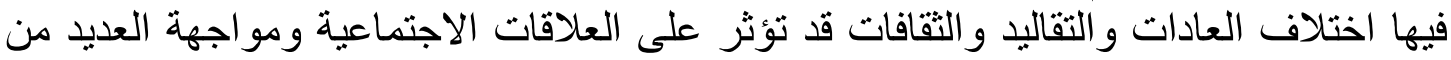

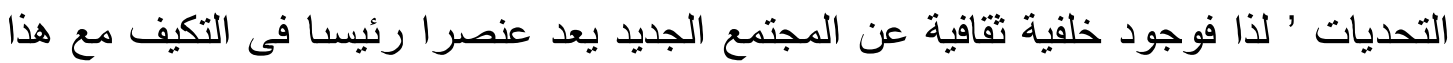

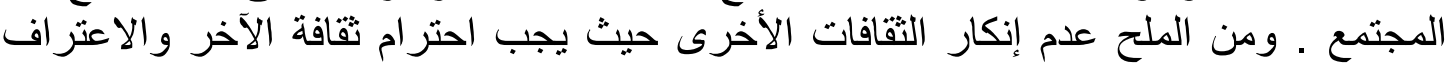

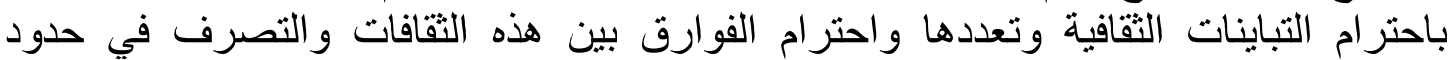

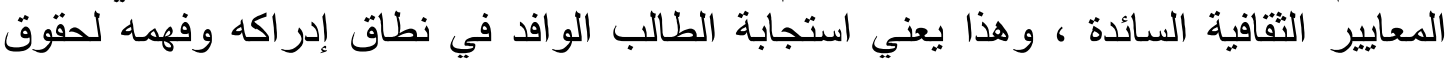

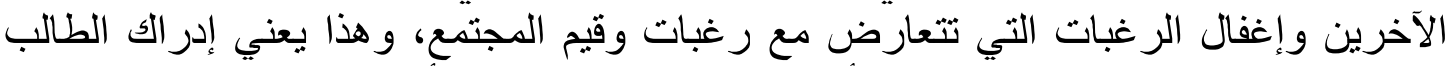

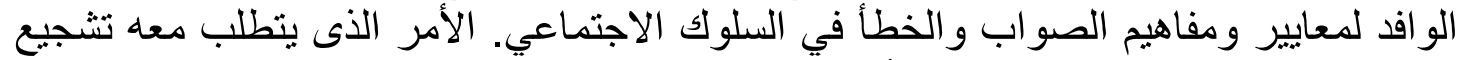

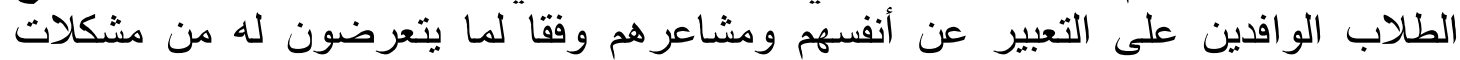

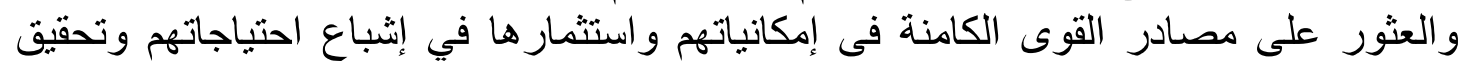

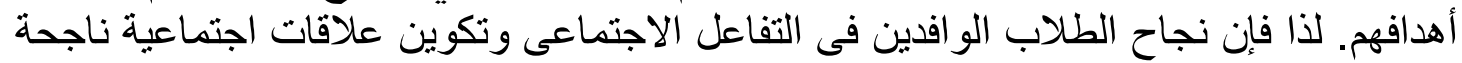
تزيد من فرصهم في التحصيل العلمى وتو الفقهم فى الحئ فئاة الجامعية الجديدة. ولعل عمل الباحثة كعضو بمكتب الو افدين على مستوى الجامعة والقيام بالإشر اف على الطلاب

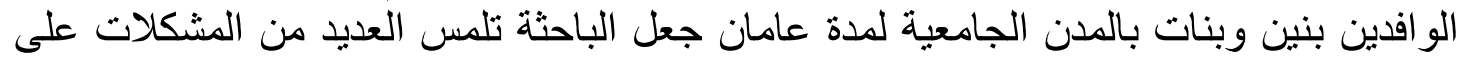

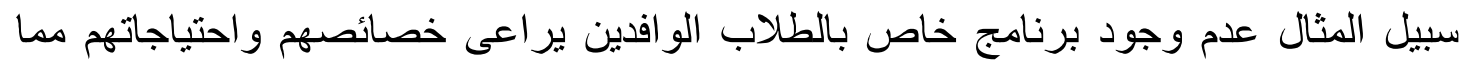

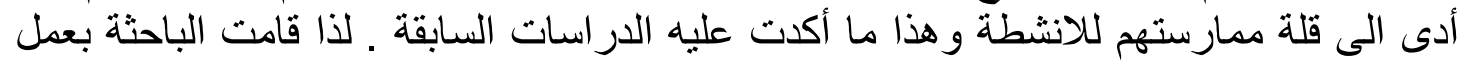

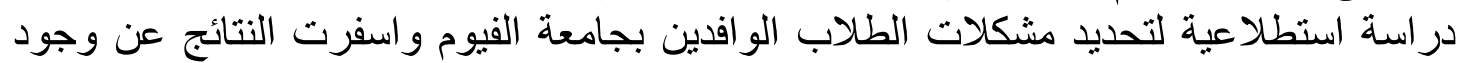

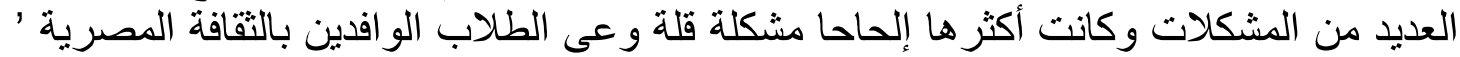

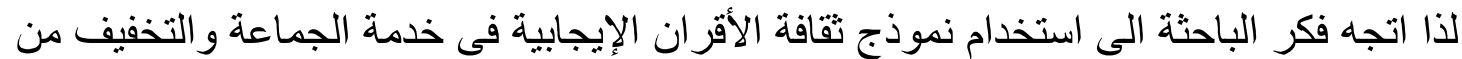

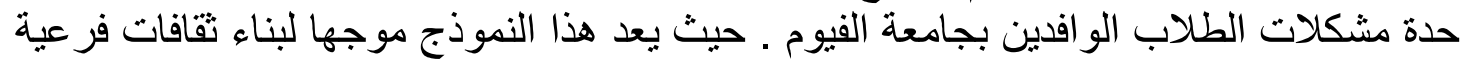
إيجابية حيث يركز على التفاعل الجماعى الموجه بين الطلاب الوافدين ويستهدف تدعيم القيم والاتجاهات الايجابية . 
2- مفاهيم الدراسة:

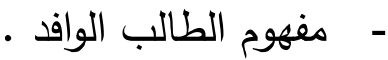

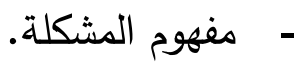

- مفهوم مشكلة قلة الوعي بالثقافة المصرية لدى الطلاب الوافدين بجامعة الفيوم.

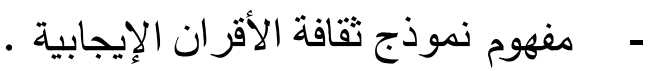

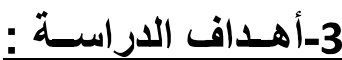

اختبار فاعلية نموذج ثقافة الأقران الايجابية في خدمة الجماعة في التخفيف من حدة مشكلة قلة وعى الطلاب الوافدين بجامعة الفيوم بالثقافة المصرية ".

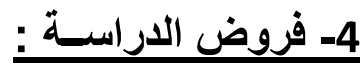

توجد فروق ذات دلالة إحصائية بين استخدام نموذج ثقافة الأقران الايجابية في خدمة الجماعة والتخفيف من مشكلة قلة وعى الطلاب الوافدين بالثقافة المصرية.

\section{الإجـراعات المنـهجية للاراســة :}

5- نـــوع الاراســة : تتنمي هذه الدراسة إلى نمط الدراسات التجريبية ، وهى من أنسب أنواع الدراسات لاختبار فاعلية نموذج ثقافة الأقران الايجابية فى خدمة الجماعة فى التخفيف من الته

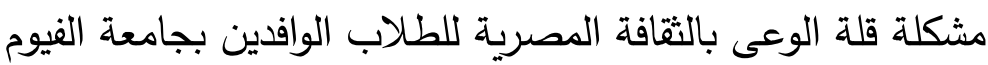

\section{6- المنهـج المستخدم في الدراسـة :}

تستند الدراسة الراهنة إلى المنهج التجريبى لمعرفة تأثير نموذج ثقافة الأقران الايجابية فى خدمة

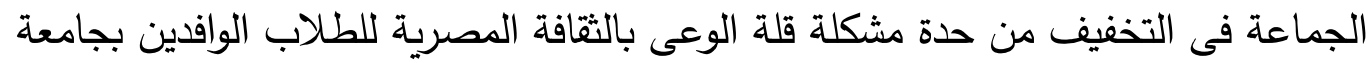

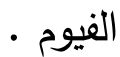

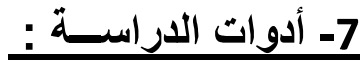

اعتمدت الباحثة فى الدراسة الراهنة على مقياس فعالية نموذج ثقافة الأقران الإيجابية فى خدمة الجماعة فى التخفيف من مشكلة مشكلة قلة الوعى بالثقافة المصرية للطلاب الوافدين بجامعة الفيوم من إعداد الباحثة مطبق على الطلاب الوافدين بجامعة الفيوم' وتحليل محتوى التقارير الدورية وذلك للتحليل الكيفى للدراسة. 


\section{8- مجـــالات الاراســــة :}

المجال المكاني : تم تطبيق الدراسة بالمدينة الجامعية للطالبات بجامعة الفيوم. المجال البشرى : عينة من الطلاب الوافدين المقيمين بالمدينة الجامعية للطالبات بجامعة الفيوم

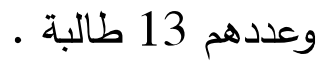
المجال الزمني : فترة إجراء الدراسة. و - نتائج الدراسة:

فى ضوء اطلاع الباحثة على النتائج الكمية المرتبطة بمقياس الدراسة 'ومن خلال تحليل محتوى التقارير الدورية فقد خلصت الباحثة الى تحقق صحة فروض الدراسة وذلك كالاتى :

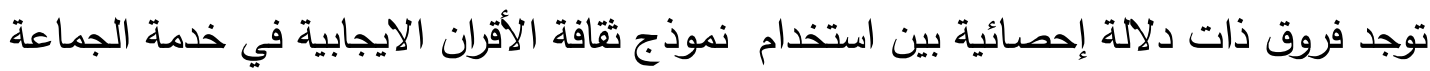
والتخفيف من مشكلة قلة وعى الطلاب الوافدين بالثقافة المصرية.

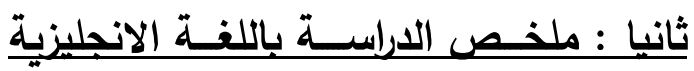

\section{Summary of Study}

\section{study problem:}

Societies and cultures are no longer closed in on themselves and one of the most important aspects of communication between different cultures is to study abroad. Therefore, Egypt took care to strengthen its relations with different countries of the world, and it concluded cultural exchange treaties, including Fayoum University. This makes it imperative for the university to maintain competitiveness in attracting foreign students, adapting to the multiculturalism of university life, meeting their needs and alleviating their problems. Foreign students, when they move from one cultural environment to another in which different customs, traditions and cultures appear, may affect social relations and face many challenges. Therefore, having a cultural background about the new society is a major element in adapting to this society. It is urgent not to deny other cultures as the culture of the other must be respected, recognition of respect for cultural differences and their plurality, respect for the differences between these cultures and act within the limits of prevailing cultural norms. This means that the incoming student responds within the scope of his awareness and understanding of the rights of others and neglecting the desires that contradict the desires and values of society, and this means the incoming student's awareness 
of the standards and concepts of right and wrong in social behavior. This requires encouraging foreign students to express themselves and their feelings according to the problems they are exposed to, find the sources of the forces inherent in their potential and invest them in satisfying their needs and achieving their goals. Therefore, the success of international students in social interaction and the formation of successful social relationships increases their chances of educational achievement and their compatibility in the new university life. Perhaps the researcher's work as a member of the expatriate office at the university level and supervising foreign students, boys and girls, in university cities for two years, made the researcher touch many problems, for example the lack of a special program for foreign students that takes into account their characteristics and needs, which led to their lack of practice of activities and this is confirmed by previous studies. Therefore, the researcher conducted an exploratory study to determine the problems of expatriate students at Fayoum University, and the results resulted in the presence of many problems, the most urgent of which was the problem of lack of awareness of foreign students about Egyptian culture.

Therefore, the researcher's thought tended to use the positive peer culture model in community service and alleviate the problems of international students at Fayoum University. As this model is directed at building positive subcultures, as it focuses on directed group interaction between international students and aims to reinforce positive values and trends.

\section{Study concepts:}

The concept of the incoming student

The concept of the problem

The concept of the problem of lack of awareness of Egyptian

culture among international students at Fayoum University

The concept of the positive peer culture model

\section{Study objectives:}

Test the effectiveness of the positive peer culture model in serving the group in alleviating the problem of the lack of awareness of foreign students at Fayoum University about Egyptian culture.

Study hypotheses: 
There are statistically significant differences between the use of a positive peer culture model in community service and alleviating the problem of the lack of awareness of foreign students about Egyptian culture.

\section{She methodological procedures of the study:}

Type of study: This study belongs to the type of experimental studies, and it is one of the most appropriate types of studies to test the effectiveness of the positive peer culture model in serving the group in alleviating the problem of lack of awareness of Egyptian culture for international students at Fayoum University.

\section{Curriculum used in the study:}

The current study is based on the experimental approach to find out the effect of the positive peer culture model in community service in alleviating the problem of lack of awareness of Egyptian culture for international students at Fayoum University.

\section{Study Tools:}

In the current study, the researcher relied on the measure of the effectiveness of the positive peer culture model in serving the group in alleviating the problem of lack of awareness of Egyptian culture for incoming students at Fayoum University.

\section{Fields of study:}

Spatial domain: The study was applied in the university campus for female students at Fayoum University.

The human domain: a sample of 13 female students residing in the University City for Female Students at Fayoum University.

Time domain: the period of study.

\section{Pesults:}

In light of the researcher's knowledge of the quantitative results related to the scale of the study, and through analyzing the content of the periodic reports, the researcher concluded that the study hypotheses were validated as follows, There are statistically significant differences between the use of a positive peer culture model in community service and alleviating the problem of the lack of awareness of foreign students about Egyptian culture. 


\section{المبحث الأول : الاطار النظرى للاريسة}

أولاً : مشكلة الدراســة وأهميتها:

إن المجتمعات والثقافات المختلفة لم تعد منغلقة على نفسها معزولة عما يدور حولها من متغيرات فى جميع المجالات وذلك فى ظل ظروف العصر الحديث والتقدم العلمي والتكنولوجي ولعل من أهم مظاهر الاتصال بين تلك المجتمعات والثقافات المختلفة هو الدراسة بالخارج , فلا يقتصر إرسال الطلاب إلى بلد آخر على الجوانب التعليمية فقط بل يتعدى ذلك إلى التعرف على الجوانب الثقافية والاجتماعية والاقتصادية ما يحقق المواطنة العالمية حيث يمكن أن تستخدم عملية إرسال الطلاب للدراسة بالخارج كوسيلة للتعاون بين الأمم والثعوب فى مختلف المجالات. والحفاظ على القدرة التتافسية في جذب الطلاب الوافدين يحتم على الجامعات والكليات أن تتكيف مع تعدد الثقافات داخل الحياة الجامعية وتلبية احتياجاتهم, وفى الوقت نفسه هناك فائدة كبيرة من

تعزيز الإلمام بالثقافات العالمية المختلفة.

وهناك ضرورة لجذب الطلاب الأجانب من دول العالم المختلفة للدراسة في مصر بالإضافة إلى إدخال البعد الدولي فى مناهج وأساليب التعليم والتدريب , وإعداد الطلاب للتعامل مع القضايا الدولية وللعمل فى بيئة تتسم بتعدد الثقافات. إن انتقال الطلاب خارج نطاق نشأتهم لمجتمع تعليمي آخر فى وطن آخر بمثابة ضغطا سواء فى العلاقات الاجتماعية والتفاعلات وضغوط جديدة لم يعتادوا عليها سابقا بسبب فقدان العلاقات فضلا عن مواجهة مظاهر تقافية مختلفة إلى الحد الذي قد ينعكس على تحصيلهم الدراسي وتوافقهم الشخصي الاجتماعي.

والمجتمع المتعدد الثقافات يسمح بالاندماج حيث يصبح فى قدرة الوافدين الاحتفاظ ببعض مكونات ثقافتهم الوطنية الأمر الذي يدعو إلى تكافؤ الفرص ومناهضة التمييز ومصدرا للتبادل والإبداع والتعرف على الثقافات الأخرى من عادات وتقاليد وقيم والاحترام المتبادل بين الثقافات , كما أن معرفة كيفية تأثير الثقافة علي القرارات والسلوك اليومي تقدم إطار مرجعي للفهم فالرؤية العالمية للأفراد الذين يختلفون عنك وانفتاح علي التتوع الثقافى • وهو ما يعنى التصرف في حدود المعايير الثقافية واستجابة الفرد في نطاق إدراكه وفهمه لحقوق الآخرين وإغفال الرغبات التي تتعارض مع رغبات وقيم المجتمع، وهذا يعني إدراك الفرد لمعايير ومفاهيم الصواب والخطأ في

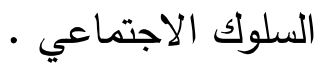
وهذا ما أكدت عليه دراسة (دينيس دولان Donlan 1997 حيث استهدفت الدراسة التعرف على عملية التكيف الثقافي لدى الطلاب الأجانب بالجامعات الأمربكيةحيث أكدت نتائج 
الدراسة وجود صعوبات فى عملية التكيف الثقافى وفى اللغة والنظام الاكاديمى للجامعة الذى يدرس وهو ما يتطلب ضرورة تتمية التكوين اللغوي للطلاب فى بلادهم قبل السفر • وكذلك أشارت إليه دراسة (جنكيز وجالوى 2009 (Jenkins,R.,Galloway حيث استهدفت الدراسة التعرف على مشكلات التكيف التقافي للطلاب الوافدين بجامعات تايوان وأكدت نتائج الدراسة على وجود مشكلات في التكيف الثقافي للطلاب الوافدين .

وهذا ما تتاولته دراسة عبد الراضي مخلف حمدي أحمد 2003 بعنوان " الصورة الذهنية لمصر لدى المسلمين غير العرب دراسة ميدانية على عينة من الطلاب الوافدين بجامعة الأزهر " هدفت الدراسة إلى قياس الصورة الذهنية لمصر والمصريين لاى المسلمين غير العرب وخاصة الطلاب الوافدين على جامعة الأزهر , وتوصلت نتائج الدراسة إلى أن الغالبية العظمى من الطلاب الوافدين كونوا صورة ذهنية لمصر قبل مجيئهم إليها حيث تفوقت الصورة الايجابية على السلبية فى حين استبدلوا هذه التصورات بعد المجيء إلى مصر بتصورات سلبية . وقد أكدت على ذلك دراسة عثمان محمد محمد نصر 2017 بعنوان " إسهامات طربقة العمل مع الجماعات فى إثباع الحاجات النفسية والاجتماعية للطلاب الوافدين "حيث استهدفت الدراسة تحديد الحاجات النفسية والاجتماعية للطلاب الوافدين وتحديد البرامج والأنشطة التي تقدم لإشباع الحاجات النفسية والاجتماعية للطلاب الوافدين والحاجة إلى المعرفة والثقافة. وتناولته كذلك دراسة على يحي يحي 2013 بعنوان " إسهامات البرامج الجماعية في خدمة الجماعة في تتمية العلاقات الاجتماعية للطلاب الوافدين بجامعة الأزهر" واستهدفت الدراسة التعرف على درجة ممارسة الطلاب الوافدين للبرامج الجماعية والتعرف على طبيعة إسهامات البرامج الجماعية فى تتمية العلاقات الاجتماعية للطلاب الوافدين وأكدت نتائج الدراسة على وجود فروق من وجهة نظر الأخصائيين الاجتماعيين والطلاب على درجة ممارسة البرامج

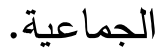

ويواجه الطلاب الوافدين العديد من التحديات والمخاوف الاجتماعية كالقلق حول أسلوب حياتهم الجديدة من قبول ومواجهة المجتمع وثقافته والتكيف معها. لذا فهناك أهمية لتلقى التدعيم الاجتماعي والنفسي للتكيف الاجتماعي والثقافي والمعيشي والاكاديمى وكذلك التكيف مع اللغة والعادات والأعراف والتعرف على أسلوب الحياة الجديد حيث الانتقال الى ادوار اجتماعية جديدة • إن كل بيئة تحتوى على سمات ثقافية مميزة لها وتتمثل تلك السمات فى بعض أنماط السلوك والعادات والتقاليد وغيرها من الأنماط الأخرى , وهذا ينطبق بطبيعة الحال على الطلاب الوافدين 
الذين يحملون أنماطا ثقافية وعادات سلوكية تميز بيئاته والتي تختلف عن البيئة الجديدة القادمين إليها. الأمر الذي يفسر ضرورة أن يكون لدى الطلاب الوافدين تجربة ايجابية وان يكون لايهم نهج عمل جماعي حيث لابد أن يتم تزويدهم بتجربة تعليمية ايجابية والاهتمام بالبرنامج الاكاديمى المقدم للطلاب الوافدين تجنبا للإحباط ومن اجل تشجيع المنافسة التعليمية داخل الجامعة وحتى تكون مصدر جذب للطلاب الوافدين •

إن طلاب المنح التعليمية ( الوافدين ) يجب أن يستوعبوا ضرورة أن يبذلوا المجهود فى الحياة الجامعية الجديدة كما يجب عليهم أن يكونوا على وعى بضرورة التكيف مع بلد جديد وان غيرهم من الطلاب الوافدين الذين سبقوهم قد واجهوا نفس التحديات وتم تبادل الخبرات والتكيف مع الثقافة الجديدة واختلاف اللغة. والتعليم داخل الجامعة يؤدى إلى تعديل السلوك لدى الطلاب الوافدين وتدعيم القيم والاتجاهات البناءة والمساهمة في توفير القدوة الحسنة بغرس الاتجاهات السليمة لاى الطلاب الوافدين ونقل التراث الثقافي وتتظيم المعلومات والحقائق التي تساعد الطلاب الوافدين على التصرف في المواقف التي تؤثر في حياتهم فالطالب الوافد وتواجده في هذه البيئة الجديدة يكتسب المعايير السلوكية التي تحدد فيما بعد سلوكه الاجتماعي وتقبله المجتمع الجديد الذي يقيم فيه وقدرته على التفاعل وتكوين العلاقات الاجتماعية الناجحة مع الآخرين خاصة وأن السلوك قابل للتعديل والتحسين . إن القدرات الثخصية للطلاب الوافدين وخبراتهم ووجود علاقات وصداقات وطيدة وكذلك وجود خلفية ثقافية عن المجتمع الجديد هي بمثابة عناصر أساسية للتكيف مع البيئة الجديدة وفى الوقت ذاته تعمل كعوامل مساعدة لمواجهة الصعوبات . وهناك ضرورة من استثمار أوقات الطلاب الوافدين وتقوية أواصر العلاقات الاجتماعية والصداقات بينهم وبين غيرهم من الطلاب الوافدين الآخرين والطلاب المصريين مما يعمل على إزالة النزعة العنصرية بين الطلاب الوافدين والطلاب المصريين وتتمية التفاعل الجماعي والذي يؤثر بدورة فى تشكيل الاتجاهات الايجابية نحو جامعة الفيوم • ويعد نموذج ثقافة الأقران الايجابية في خدمة الجماعة موجها لبناء ثقافات فرعية ايجابية للطلاب الوافدين حيث يركز على التفاعل الجماعي الموجه لجماعة الأقران ويستهدف تدعيم كل من القيم والاتجاهات الايجابية وتقدير الذات لجعل تأثير الأقران تأثيرا ايجابيا .حيث أن كل شخص لديه الحاجة للشعور بأنه مهم وأن الآخرين مهتمين به وبالتالي فيجب أن يمنح كل شخص الفرصة لكي يساعد نفسه ويساعد الآخرين. 
ويمكن للباحثة أن تعرض ما أسفرت عنه نتائج الدراسة الاستطلاعية وجود مشكلات يعانى منها الطلاب الوافدين بجامعة الفيوم أهمها مشكلة قلة الوعى بالثقافة المصرية لدى الطلاب الوافدين . ومن هذا المنطلق وحرصـا على تحسين مستوى الخدمة المقدمة للطلاب الوافدين نحو تحقيق أهدافهم وإيمانا بالدور المنوط بجامعتنا العريقة لذا فقد اتجه فكر الباحثة الى استخدام نموذج ثقافة الأقران الايجابية فى خدمة الجماعة للتخفيف من حدة مشكلة مشكلة قلة الوعى بالثقافة المصرية لدى الطلاب الوافدين بجامعة الفيوم •

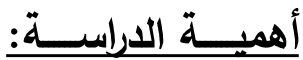

- تعد منظومة الطلاب الوافدين ذات عائد سياسي واقتصادي وثقافي مميز فهي تدعم العلاقات الدولية.

- - تزايد أعداد الطلاب الوافدين بجامعة الفيوم يحتم علينا البحث عن أفضل السبل لمواجهة مشكلاتهم وتلبية احتياجاتهم( وفقا لإحصائية الإدارة العامة لثئون التعليم والطلاب بجامعة الفيوم / إدارة الوافدين بجامعة الفيوم 2020 ) . - تقوية العلاقات بين مصر ودول العالم الموفود منها وضرورة تقديم خدمات للطلاب الوافدين بجامعة الفيوم ترقى بمستوى اسم بلدنا الحبيب , وبالتالي استقطاب وافدين جدد . - إستراتيجية جامعة الفيوم التى تبنت محورا حول الطلاب الوافدين وأهمية دراسة المشكلات المتعلقة بهم . - عدم وجود أي دراسة تتاولت الطلاب الوافدين بجامعة الفيوم فى حدود علم الباحثة . - ندرة الدراسات والبحوث فى حدود علم الباحثة فى طريقة العمل مع الجماعات التي تتاولت مشكلات الطلاب الوافدين على مستوى الجامعات المصرية. - عمل الباحثة كعضو فى مكتب الوافدين على مستوى جامعة الفيوم والإشراف على الطلاب الواقدين ( بنين - بنات ) بالمدن الجامعية لمدة عامان , والتعامل المباشر معهم ولمس بعض المشكلات التي تستدعى الدراسة مما يساعد فى التعمق فى فهم مشكلة الدراسة , وإجراء الدراسة. - اتفاق جميع الدراسات السابقة على وجود مشكلات يعانى منها الطلاب الوافدين تعوق توافقهم

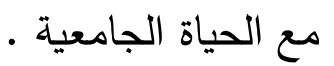


- اختلاف خصائص عينة البحث فى الدراسات السابقة عن خصائص مجتمع البحث فى الدراسة الراهنة كاختلاف الثقافة والعادات والتقاليد واللغة والدين .

- - تأكيد بعض نتائج الدراسات السابقة على عدم تفعيل كافة البرامج مع الطلاب الوافدين .

- - تأكيد بعض نتائج الدراسات السابقة على قلة ممارسة الطلاب الوافدين للأنشطة الطلابية - محاولة التوصل لنتائج ومقترحات من إجراء هذه الدراسة تقيد الأجهزة المعنية بالوافدين بجامعة الفيوم •

ثانيا : مفاهيم الارباسة: مفهوم المشكلة :

تعرف المشكلة فى قاموس الخدمة الاجتماعية : " موقف تشعر به جماعة كمصدر لعدم الرضا لأعضائها حيث تسلم هذه الجماعة بأن هناك تعديلا يجب إجراؤه ومن ثم تتحرك الجماعة أو الأفراد داخل الجماعة لإحداث تغيير " لائم

\section{التعريف الاجر ائى للمشكلة : مثكلة مشكلة قلة الوعي بالثقافة المصرية لدى الطلاب الوافدين بجامعة الفيوم:} "هي اضطرابات في إدراك الواقع الاجتماعي الجديد بما يشمله من عادات وتقاليد مغايره يصعب التعامل معها وما يصاحب ذلك من اتجاهات سلبية نحوه وما يترتب عليه من تشكك في نظرة الزملاء وما له من تأثير على الاتصال اليومي سواء كان رمزيًا أو غير رمزي ظاهرًا أو كامنًا ويمكن التعامل مع البرامج والأنشطة في خدمة الجماعة بما تتضمنه من علاقات وتجارب وخبرات بين الطلاب الوافدين لتحقيق الأهداف". مفهوم الطالب الوافد : يعرف الطالب الوافد : " طالب من قطر ما يدرس في قطر آخر وغالبا في مستوى المرحلة الثانويـة أو التعليم العالي " .

$$
\text { التعريف الاجر ائى ( الطالب الو افد) : }
$$

- الطالب الوافد هو طالب أجنبي مغترب عن وطنه ل الا يحمل الجنسية المصرية .

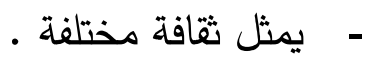


- يقيم فترة زمنية محددة في مصر طلبا للعلم في إحدى المجالات في مرحلة التعليم - يحتاج خلال هذه الفترة المناخ الملائم لتحقيق الهدف من وجوده . - يتم قيده بجامعة الفيوم سواء على منحة دراسية أو دراسة حرة .

\section{مفهوم نموذج ثقافة الأقران الايجابية:}

( مفهوم الأقران ) :هم الأصدقاء الذين يمكن أن يساعدوا وينصحوا ويمكن استخدامهم في خدمة وتدعيم الآخرين.

( مفهوم التحكم فى السلوك ) : يعتبر استخدام أسلوب التبصير من الأساليب الهامة في تعديل

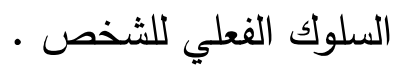

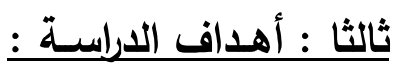

تسعى الدراسة الى " اختبار فاعلية نموذج ثقافة الأقران الايجابية في خدمة الجماعة في التخفيف من حدة مشكلة قلة الوعى بالثقافة المصرية لدى الطلاب الوافدين بجامعة الفيوم".

\section{رليعا : فروض الاراسيـة :}

توجد فروق ذات دلالة إحصائية بين استخدام نموذج ثقافة الأقران الايجابية في خدمة الجماعة والتخفيف من مشكلة قلة الوعى بالثقافة المصرية لاى الطلاب الوافدين بجامعة الفيوم".

\section{خامسا : أوجه الاستفادة من نموذج ثقافة الأقران في الدراسة الراهنة :}

- تساعد جماعة الأقران الإيجابية فى تتمية الوعى الثقافى والإجتماعى بين الطلاب

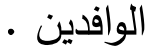

- - أن تكون الثقافة التى ينتمى اليها الطلاب الوافدين محققة لحاجاتهم وبالتالى يشعرون بالرضا والقبول وبالتالى تقابلهم الجماعة بالقبول - - تساهم جماعة الاقران الايجابية فى اكتساب الميراث الثقافى للطلاب الوافدين الذى

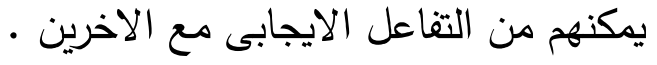


- يساهم النموذج في فهم وتحليل التقاعل الجماعي الموجه بين الطلاب الوافدين وتأثير

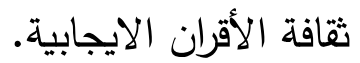
- ما يساهم هذا النموذج في إحداث تغيير في شخصية الطلاب الوافدين من خلال وصف الاستجابات تجاه المشكلات التي يواجهونها. - يساعد هذا النموذج الاخصائى في إمكانية القدرة على تغيير القيم والاتجاهات والسلوكيات لدى الطلاب الوافدين ولكن بنسب مختلفة . - يجب أن يمنح الطلاب الوافدين الفرصة لمساعدة أنغسهم نحو تحقيق أهدافهم وكذلك

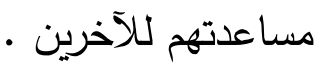
- اتاحة الفرصة للطلاب الوافدين لتكوين علاقات اجتماعية مع زملائهم من الجنسيات المختلفة وكذلك زملائهم من الطلاب المصريين . - تبادل الخبرات والآراء والهشورة بين الطلاب الوافدين . - ممارسة الأنشطة بشكل جماعي مما يعدم الاستمتاع بالخدمات الترويحية المقدمة وتفعيل

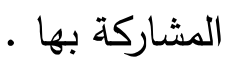
- يمكن عن طريق جماعة الاقران الايجابية تعديل وتغيير السلوك غير المرغوب فيه عن

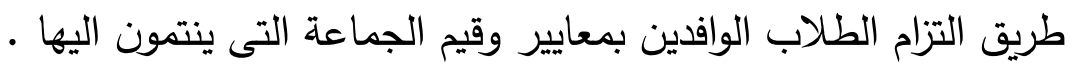
- تساعد جماعة الأقران الايجابية الطالب الوافد على تحقيق الرغبات والاهداف التى يعجز عن تحقيقها بمفرده فهى تدعم التعاون والمشاركة وممارسة الأنشطة الجماعية. - تساعد جماعة الاقران الايجابية الطلاب الوافدين على فهم وادراك طبيعة انماط الحياة السلوكية فى ظل عالم متغير والذى بدوره يؤدى الى تتمية المسئولية الاجتماعية لايهم. - مساعدة الطلاب الوافدين على فهم طبيعة ادوارهم الاجتماعية ما يدعم المسئولية الاجتماعية الفردية والجماعية. - تساعد جماعة الاقران الايجابية الطلاب الوافدين على التعبير عن ارائهج وافكارهم ومعتقداتهم وتصوراتهم وانفعالاتهم بهدف الوقوف عليها والعمل على تصحيحها فى ضوء العقل الجمعى من خلال المناقثة الجماعية . 
- - تسهم الجماعة فى وضع محددات السلوك لدى الطلاب الوافدين من خلال مناقثة وتوضيح ما يجب فعلة وما لا يجب فى ضوء القيم والقواعد والاعراف والمعتقدات والتقاليد , والتى تتظم فى سياقها ثقافة المجتمع وهو ما يعبر عنه بالضبط الاجتماعى - مساعدة الطلاب الوافدين على فهم المؤثرات الخارجية وكيفية التعامل معها فى اطار القيم الدجمعية وتدعيم الذات وتتمية الاتجاهات الايجابية واكتساب الخبرات والمعارف المرتبطة بالحقوق والواجبات ما يتيح الفرصة للمشاركة الفعلية للأعضاء داخل الجماعة - تتيح جماعة الاقران الايجابية للطلاب الوافدين الفرصة لاكتساب الخبرات الحياتية

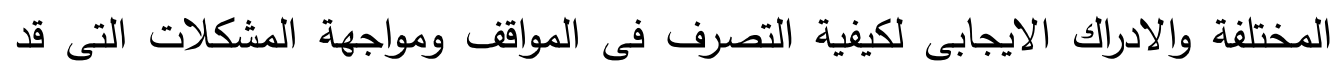
يواجهونها داخل الحياة الجامعية أو خارجها ـ

\section{المبحث الثانى}

\section{الاجراءات المنهية ومناقشة نتائج الدراسة}

أولا: نــوع الدراسـة: :

تتنمي هذه الدراسة إلى نمط الدراسات التجريبية لاختبار فاعلية نموذج ثقافة الأقران الايجابية فى خدمة الجماعة فى التخفيف من مشكلة قلة الوعى بالثقافة المصرية لاى الطلاب الوافدين

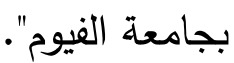

\section{ثانيا:المنهـج المستخدم في الإراسـة :}

تستند الدراسة الراهنة إلى المنهج التجريبى لـعرفة تأثير نموذج ثقافة الأقران الايجابية فى خدمة

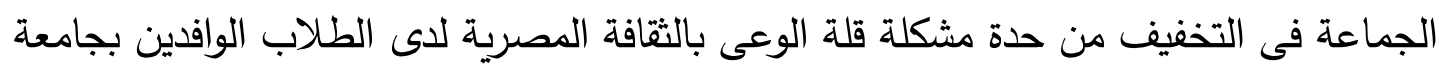

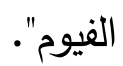

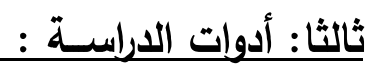


اعتمدت الباحثة على مقياس فعالية نموذج ثقافة الأقران الإيجابية فى خدمة الجماعة فى التخفيف من مشكلة قلة الوعى بالثقافة المصرية لدى الطلاب الوافدين بجامعة الفيوم".من إعداد الباحثة ُوتحليل محتوى التقارير الدورية وذلك للتحليل الكيفى للدراسة. التحقق من صدق وثبات المقياس : صدق المقياس:استخدمت الباحثة أسلوبين للتحقق من صدق المقياس : - الصدق الظاهرى : حيث تم تحكيم المقياس واستبعاد العبارات التى تقل نسبة الاتفاق

$$
\text { عليها عن (85\%). }
$$

- الصدق الذاتى : تم حساب الجذر التربيعى لمعامل ثبات المقياس:

ثبات المقياس:

اعتمدت الباحثة على طريقة إعادة الإختبار للتأكد من ثبات المقياس ’وذلك من خلال تطبيق المقياس على عينة قوامها (15) طالب وافد وقامت الباحثة بإعادة تطبيق المقياس بعد خمسة عشر يوما على نفس العينة واستخدمت الباحثة معامل ارتباط (سبيرمان) لتحديد معامل الثبات

لبعا :الأساليب الإحصائية المستخدمة: المعادلات الاحصائية

اختبار ( ت ) لتعرف دلالة الفروق بين متوسطين غير مرتبطين (ن-ن2) (التجريبية-

$$
\text { (الضابطة) }
$$

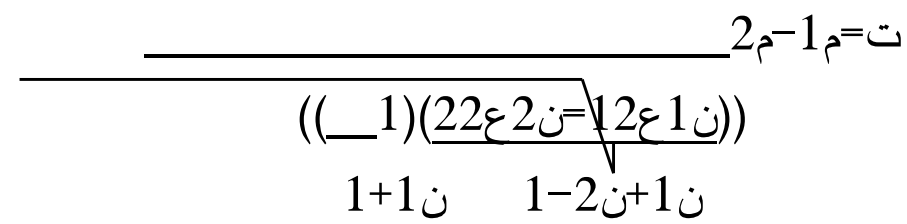

اختبار (ت) فى حالات العينات المرتبطة ( مجموعة واحدة قبلى وبعدى ) وذلك لحساب

فروق التطبيقين القبلى والبعدى لادوات البحث وذلك وفقا للقانون الاتى:

$$
\text { | }
$$




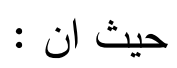

م ف = مجموع فروق القيم بين التطبيقين القبلى والبعدى (مجن ف)

عددهم

مج ح 2 ف = مجموع مربعات انحرافات القيم عن متوسط الفروق

ن: عدد افراد العينة

تم استخدام الحزمة الاحصائية للعلوم الاجتماعية الأصدار 21 فى حساب المعادلات

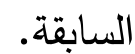

خامسا :مجــالات الدراســة :

1) المجال المكاني :تم تطبيق الدراسة بالمدينة الجامعية للطالبات بجامعة الفيوم. وقد تم اختيار المجال المكاني نظرا للمبررات التالية:-

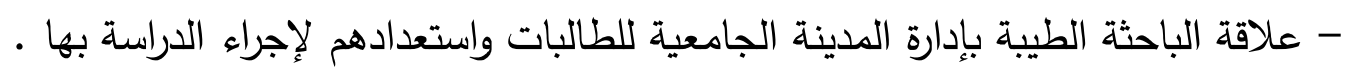
- توافر المكان المناسب لتطبيق اجتماعات الدراسة وتتفيذ الانثطة الدختلفة بالبرنامج . - توافر العينة المناسبة لتطبيق الدراسة .

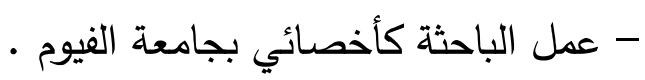
- إقامة الطلاب الوافدين بالمدينة الجامعية يسهل تواجدهم لتطبيق البيق البرنامج .

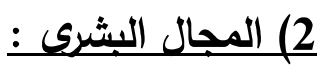

*الاطار العام للمعاينة : الطلاب الوافدين بجامعة الفيوم وعددهم (205) طالب وافد

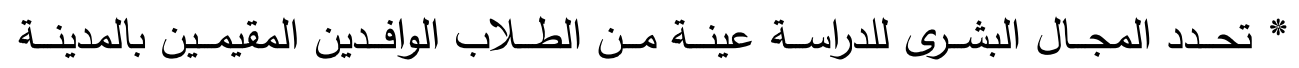

الجامعية للطالبات بجامعة الفيوم وعددهم 13 طالبة . شروط اختيار العينة: - أن يكون الطالب يحمل الجنسية غير المصرية .

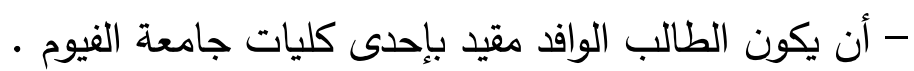
- ان يكون الطالب مقيم بالمدينة الجامعية . 3) المجال الزمني : فترة إجراء الدراسة.

\section{سادسا : عرض ومناقثة النتائسج الاحصائية للدراسـة :}

تسعى الدراسة الحالية الى اختبار صحة الفرض التالى: توجد فروق ذات دلالة احصائية بين استخدام نموذج ثقافة الاقران الايجابية فى خدمة الجماعة والتخفيف من مشكلة التهات 
مشكلة قلة الوعى بالثقافة المصرية لدى الطلاب الوافدين بجامعة الفيوم".ولاثبات صحة الفرض فقد قامت الباحثة بمناقشة النتائج كالتالى :

$$
\text { جدول (1) }
$$

الفروق بين الجماعة الضابطة والتجريبية في القياس القبلى لمشكلة

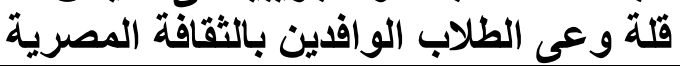

\begin{tabular}{|c|c|c|c|c|c|}
\hline مستوى الدلالة & $\mathrm{T}$ & الانحراف الهعيارى & الهتوسط الحسابى & الجماعة & م \\
\hline \multirow[b]{2}{*}{0.688} & \multirow[b]{2}{*}{0,405} & 2,40 & 35,66 & الضاططة & 1 \\
\hline & & 2,08 & 36,01 & التجريبية & 2 \\
\hline
\end{tabular}

يتضح من الجدول عدم وجود فروق ذات دلالة إحصائية بين متوسطي درجات المبحوثين

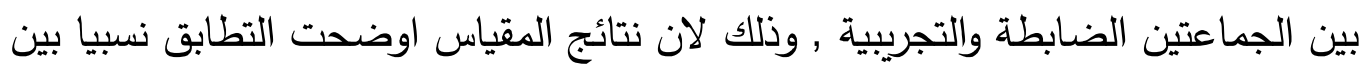
متوسطات درجات المبحوثين فى القياس القبلى للجماعتين , فالمتوسط الحسابى للجماعة

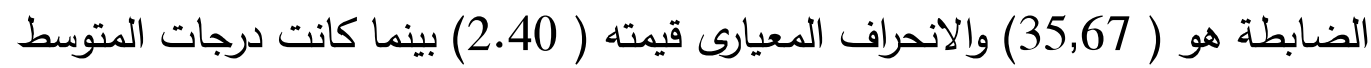
الحسابى للجماعة التجريبية هو ( 36,01 ) والانحراف المعيارى مقدارة ( 2,08) , وهذه

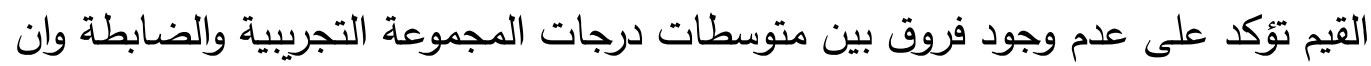

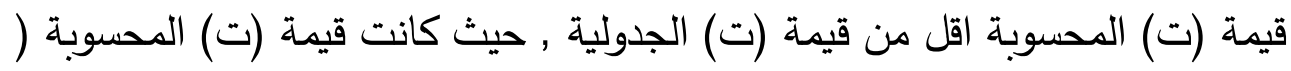
0.405) وهى غير دالة احصائيا وهذا يرجع الى عدم تتفيذ الباحثة برنامج التخخل المهنى مع الجماعة التجريبية . ماهى

\section{جدول (2)}

يوضح استجابات المبحوثين فى القياس القبلى حول مشكلة قلة وعى الطلاب الوافدين بالثقافة

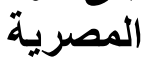

\begin{tabular}{|c|c|c|c|c|c|c|}
\hline \multicolumn{3}{|c|}{ الجهاعة التجريبية } & \multicolumn{3}{|c|}{ الجماعة الضابطة } & \multirow[b]{2}{*}{ البــــــــان } \\
\hline y: $\frac{2}{3}$ & $\overline{3} 3$ & $\frac{2}{3}$ & y: $\frac{\alpha}{3}$ & $\bar{y} 3$ & $\frac{2}{3}$ & \\
\hline 149 & 62 & 89 & 153 & 59 & 88 & مجموع درجات استجابات الهقياس \\
\hline 7.45 & 3.1 & 4.4 & 7.65 & 2.95 & 4.4 & المتوســط \\
\hline 49.67 & 20.67 & 29.67 & 51 & 19.67 & 29.33 & النسبة الهئوية \\
\hline & & 49.56 & & & 47.44 & القوة النسبية للبعد \\
\hline
\end{tabular}

يتضح من الجدول عدم وجود اختلافات بين المبحوثين ووجود تكافؤ نسبى بين كلا من الجماعة التجريبية والجماعة الضابطة حيث كانت القوة النسبية لقلة وعى الطلاب الوافدين بالثقافة 
المصرية للجماعة الضابطة (47.44) بينما كانت القوة النسبية للمجموعة التجريبية (49.56)

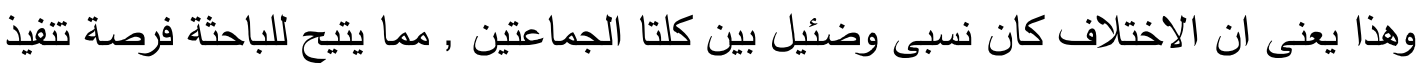

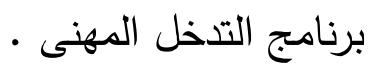

جدول(3) (3)

استجابات المبحوثين فى القياس البعدى حول مشكلة قلة وعى الطلاب الوافدين بالثقافة

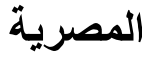

\begin{tabular}{|c|c|c|c|c|c|}
\hline مستوى الدلالة & $\mathrm{T}$ & الانحراف المعيارى & المتوسط الحسابي & الجماعة & م \\
\hline \multirow[b]{2}{*}{0.000} & \multirow[b]{2}{*}{6.25} & 3.94 & 37.74 & الضابطة & 1 \\
\hline & & 2.57 & 45.25 & التجريبية & 2 \\
\hline
\end{tabular}

تثير نتائج هذا الجدول الى انه توجد فروق ذات دلاله احصائية بين الجماعه الضابطه والجماعه التجريبيه حيث كان المتوسط الحسابي للمجموعه الضابطه هو (37.74) والانحراف المعياري قيمتاه(3.90) بينما كانت درجات المتوسط الحسابي للدجموعه التجريبيه هو(43.91) وانحراف معياري مقداره(3.94), وهذه القيم تؤكد على وجود فروق بين متوسطات درجات الهجموعه التجريبيه والضابطه وان قيمة (ت) الدحسوبه اكبر من قيمه(ت) الجدوليه حيث تقدر قيمه (ت) المحسوبه(6.25) وهي داله احصائيا وذلك يدل على اثر التذخل المهني في تتميه هذا البعد لدي اعضاء الجماعه التجريبيه.

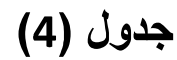

استجابات المبحوثين فى القياس البعدى حول مشكلة قلة وعى الطلاب الوافدين بالثقافة

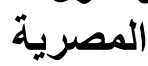

\begin{tabular}{|c|c|c|c|c|c|c|}
\hline \multicolumn{3}{|c|}{ الجماعة التجريبية } & \multicolumn{3}{|c|}{ الجماعة الضابطة } & \multirow[b]{2}{*}{ البــــــــان } \\
\hline $\begin{array}{l}\text { 年: } \\
\frac{\xi}{3}\end{array}$ & $\begin{array}{l}\bar{y} \\
1 \\
3\end{array}$ & $\frac{2}{3}$ & $\begin{array}{l}\text { 年: } \\
\frac{\xi}{2}\end{array}$ & $\begin{array}{l}\bar{y} \\
1 \\
3\end{array}$ & $\frac{2}{3}$ & \\
\hline 77 & 67 & 156 & 137 & 60 & 103 & مجموع درجات استجابات الهقياس \\
\hline 3.85 & 3.35 & 7.8 & 6.85 & 3 & 5.15 & المتوسـط \\
\hline 25.67 & 22.33 & 52 & 45.67 & 20 & 34.33 & النسبة الهئوية \\
\hline & & 82.11 & & & 50.67 & القوة النسبية للبعد \\
\hline
\end{tabular}

يتضح من الجدول وجود اختلافات بين المبحوثين بين كلا من الجماعة التجريبية والجماعة

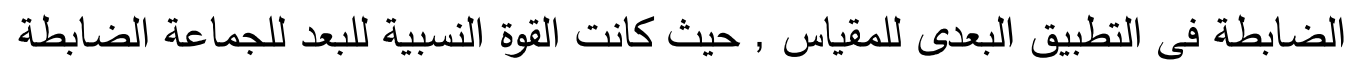
(50.67) وبمجموع اوزان (456) بينما كانت القوة النسبية للمجموعة التجريبية (82.11) 
وبمجموع اوزان (739) وهذا يعنى ان الاختلاف كان كبير بين كلتا الجماعتين وذلك نتيجة تتفيذ برنامج التخخل المهنى.

\section{جدول(5)}

يوضح استجابات الجماعة التجريبية فى كلا من القياس القبلى و البعدى حول مشكلة قلة وعى القئل الطلاب الوافدين بالثقافة المصنية المصنية

\begin{tabular}{|c|c|c|c|c|c|c|}
\hline \multicolumn{3}{|c|}{ الجماعة التجريبية } & \multicolumn{3}{|c|}{ الجماعة الضابطة } & \multirow[b]{2}{*}{ البــــــــان } \\
\hline $\begin{array}{l}\frac{y}{5} \\
\frac{2}{3}\end{array}$ & $\begin{array}{l}\bar{y} \\
1 \\
3\end{array}$ & $\frac{2}{9}$ & 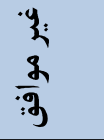 & $\begin{array}{c}\bar{y} \\
1 \\
3\end{array}$ & $\frac{2}{3}$ & \\
\hline 77 & 67 & 156 & 149 & 62 & 89 & مجموع درجات استجابات الهقياس \\
\hline 3.85 & 3.35 & 7.8 & 7.45 & 3.1 & 4.4 & المتوســـط \\
\hline 25.67 & 22.33 & 52 & 49.67 & 20.67 & 29.67 & النسبة الهئوية \\
\hline & & 82.11 & & & 49.56 & القوة النسبية للبعد \\
\hline
\end{tabular}

يتضح من الجدول وجود اختلافات بين كلا من التطبيق القبلى والبعدى للجماعة التجربية حيث

كانت القوة النسبية للبعد للقياس القبلى للجماعة التجريبية (49.56) وبمجموع اوزان (446) بينما كانت القوة النسبية للتطبيق البعدى للمجموعة التجريبية (82.11) وبمجموع اوزان (739) وهذا يعنى ان الاختلاف اصبح كبيرا وذلك نتيجة تتفيذ برنامج التذخل المهنى.

جدول(6)

يوضح القياس القبلى و البعدى للمجموعة التجريبية حول مشكلة قلة وعى الطلاب الوافدين بالثقافة المصرية

\begin{tabular}{|c|c|c|c|c|c|}
\hline مستوى الدلالة & $\mathbf{T}$ & الانحراف الهعيارى & الهتوسط الحسابي & قياس الجهاعة التجريبية & م \\
\hline \multirow[t]{2}{*}{0.000} & \multirow[t]{2}{*}{11.20} & 2.05 & 36.00 & 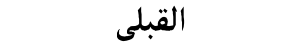 & 1 \\
\hline & & 2,57 & 45.25 & 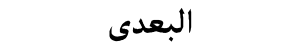 & 2 \\
\hline
\end{tabular}

تشير نتائج الجدول وجود فروق ذات دلاله احصائية بين متوسط درجات الجماعة التجريبية لصالح التطبيق البعدى للمجموعة التجريبية وذلك لان نتائج المقياس اوضحت ارتقاع متوسطات درجات الجماعة التجريبية فى القياس البعدى لارتفاع وعى الطلاب الوافدين بالثقافة المصرية , حيث بلغت قيمة (ت) المحسوبه ( 11.20) وهى اكبر من قيمه (ت) الجدوليه وهي داله احصائيا عند مستوى الدلالة . 


\section{سابعا: النتائـج العـامة للدراسـة :}

تحققت صحة الفرض الذى مؤداه : توجد فروق ذات دلالة إحصائية بين استجابات المبحوثين على المقياس قبل وبعد تطبيق برنامج التخخل المهنى بين استخدام نموذج ثقافة الأقران الايجابية في خدمة الجماعة والتخفيف من مشكلة قلة وعى الطلاب الوافدين بالثقافة المصرية. حيث أثبتت نتائج الدراسة صحة هذا الفرض فقد تبين عدم وجود فروق ذات دلالة إحصائية بين متوسطي درجات المبحوثين لبعد قلة وعى الطلاب الوافدين بالثقافة المصرية فى المقياس بين الجماعتين الضابطة والتجربيية , وذلك لان نتائج المقياس اوضحت التطابق نسبيا بين متوسطات درجات المبحوثين فى القياس القبلى لكلا من الجماعة الضابطة والجماعة التجريبية قبل تطبيق برنامج التخخل المهنى وهى غير دالة احصائيا وهذا يرجع الى عدم تنفيذ الباحثة برنامج التخخل المهنى مع الجاعة التجريبية وارجاع اى تغيير يطرأ على نتائج الجماعة التجريبية فيما بعد بالنسبة للتغير التابع الى المتغير المستقل وهو نموذج ثقافة الاقران الايجابية فى التخفيف قلة وعى الطلاب الوافدين بالثقافة المصرية . بينما بعد تطبيق برنامج التدخل المهنى فأثبتت نتلئج الدراسة أنه توجد فروق ذات دلاله احصائية بين الجماعه الضابطه والجماعه التجريبيه وهي داله احصائيا وذلك يؤكد تأثير التخخل المهني في تتميه هذا البعد لدي اعضاء الجماعه التجربييه . ومن خلال النتائج السابقه تم التأكد من صحه الفرض انه :( توجد فروق ذات دلالة احصائية بين استخدام نموذج ثقافة الاقران الايجابية فى خدمة الجماعة والتخفيف من مشكلة قلة وعى الطلاب الوافدين بالثقافة المصرية ) حيث توجد فروق ذات دلاله احصائية بين متوسط درجات الجماعة التجريبية لصالح التطبيق البعدى للمجموعة التجرببية وذلك لان نتائج المقياس اوضحت ارتفاع متوسطات درجات الجماعة التجريبية فى القياس البعدى لارتفاع وعى الطلاب الوافدين بالثقافة المصرية , وهي داله احصائيا عند مستوى الدلالة ـ أى أن برنامج التخخل المهني قد قلل من مشكلات هذا البعد لدي اعضاء الجماعه التجربييه. 


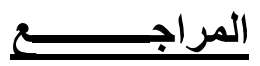

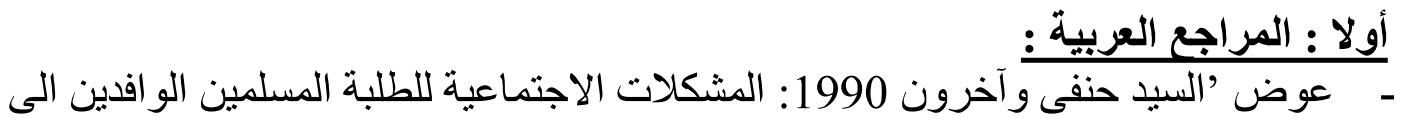
الجامعات المصرية "در اسة سسيولوجية " , جامعة الزقازيق , كلية الآداب .

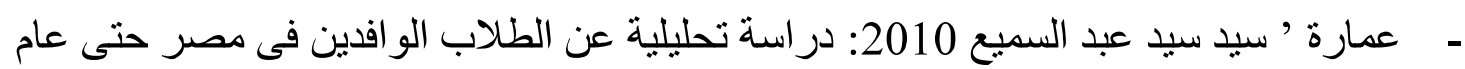

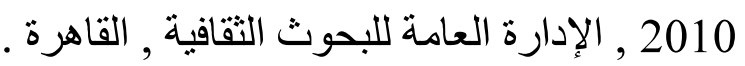

- نيازى ' عبد المجيد 2000 : أساسيات ممارسة طريقة العمل مع الجماعات , الرياض , مكتبة العبيكان .

- الصغير 'صالح بن محمد1422 هـ : " التكيف الاجتماعي للطلاب الو افدين در اسة تحليلية

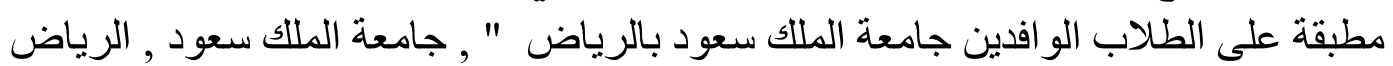

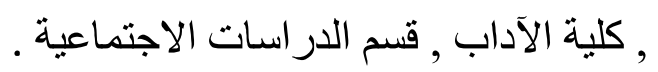

- عكاشة 'صبري 2003: بعض مشكلات التو اقق النفسي و الدر اسي المرتبطة بصعوبة القر اعة

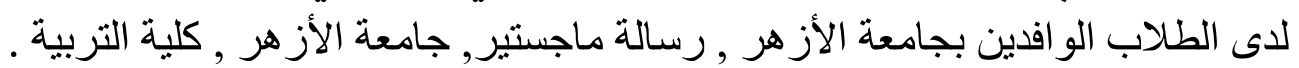
- - نجم 'ضياء الدين إير اهيم 2000 : المفهومات والعناصر الأساسية فى طريقة العمل مع الهع الجماعات , الإسكندرية , المكتبة الجامعية .

- كمال 'طارق 2005 : سيكولوجية الشباب ( تتمية الثباب اجتماعيا و اقتصاديا ) , الإسكندرية , مؤسسة شباب الجامعة .

- لطفي 'طلعت إبر اهيم 2000: جماعة الأقر ان ومشكلة التغيب عن الدراسة , بحث منشور ر مجلة شئون اجتماعية , جامعة الإمار ات , مجلد 17 , العدد 67.

عبد المحسن 'عبد الحميد 1994: الممارسة المهنية في العمل مع الجماعات , القاهرة , دار الثقافة للنشر و التوزيع .

- أحمد 'عبد الر اضي مخلف حمدي2003: " الصورة الذهنية لمصر لدى المسلمين غير

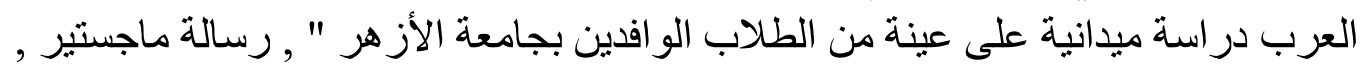
جامعة الأز هر كلية اللغة العربية ,ولة علية منية

- النوحى 'عبد العزيز 1990: المشكلات الطلابية فى المناطق الحكومية المستحدثة , مجلة در اسات الخليج والجزيرة العربية , العدد 626 (16 ابريل) .

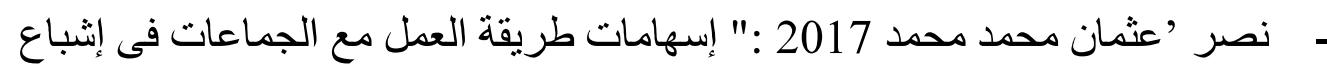
الحاجات النفسية والاجتماعية للطلاب الو افدين ", رسالة ماجستير , جامعة أسيوط , كلية الخدمة الاجتماعية قسم خدمة الجماعة. 


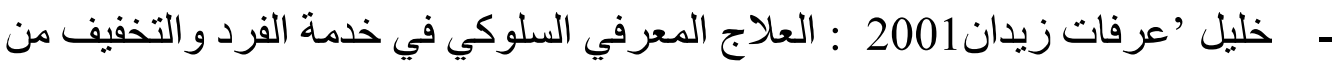

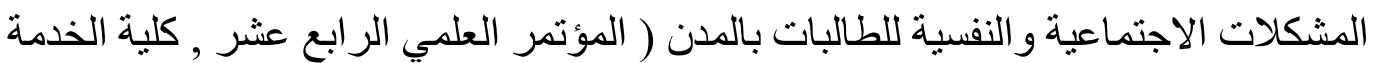
الاجتماعية , جامعة حلوان ), مارس.

- الطويل 'عزت عبد العظيم 2001 : معالم علم النفس المعاصر , الإسكندرية , دار الوفاء لدنيا الطباعة و النشر ر الطبعة الر ابعة .

- ـ راتانسى 'على 2013 : التعددية الثقافية " مقدمة قصيرة جدا " , القاهرة , مؤسسة هنداوى للتعليم و الثقافة , ط1.

ناصف 'على يحي يحي2013 : إسهامات البرامج الجماعية فى خدمة الجماعة فى تنمية

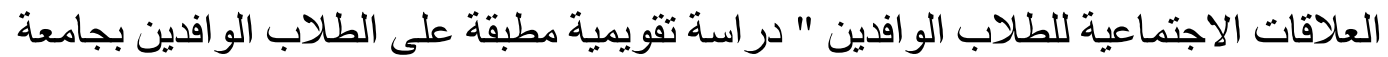

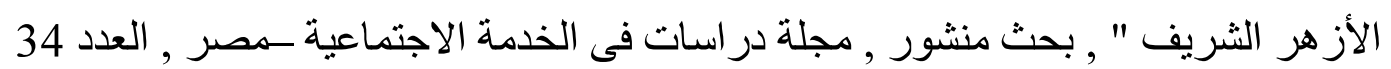

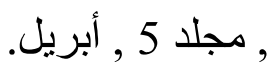
- العوفى 'عيسى سعدواخرون 2010: القاموس العربي الأول لمصطلحات علوم التفكير , دار

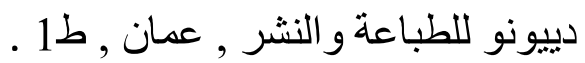

- - محمد 'غانم زكى محمد 2010: " العوامل المؤثرة على التوافق الثخصي و الاجتماعي

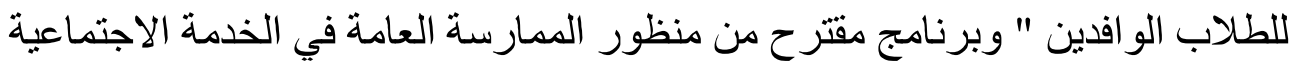

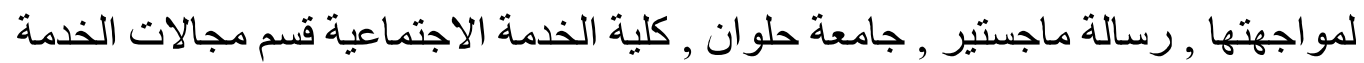

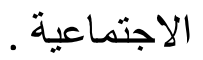
- الجو لاني ' فاديه عمر 1999: تشخيص وعلاج المشكلات الاجتماعية النفسية , الإسكندرية ,

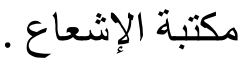
- جبريل ’ فاروق السعيد 1999 : علم النفس الاجتماعي , المنصورة , عامر للطباعة والنشر

- منقريوس ' نصيف فهمي وآخرون 2011: الاتجاهات الحديثة و التطبيقات الميدانية فى رعاية ذوى الاحتياجات الخاصة , القاهرة , المكتب الجامعى الحديث . - منقريوس ' نصيف فهمي وآخرون 2005: المحتوى العلمي و المهني للنماذج و النظريات فى في

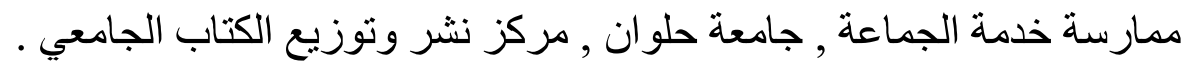
- منقريوس 'نصيف فهمي 2016: نماذج ونظريات فى ممارسة خدمة الجماعة , جامعة حلوان , كلية الخدمة الاجتماعية , قسم خدمة الجماعة . 
- محمد 'هاجر عرابي عبد الله 2016: " المساندة الاجتماعية للطلاب الو افدين وعلاقتها بالضغوط الحياتية در اسة فى إطار المدخل الايكولوجي " , رسالة ماجستير , جامعة حلوان , رابهة

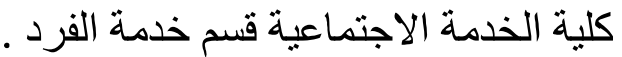

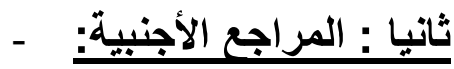

- American council on education (2012). Mapping internationalization on U.S. campuses. Retrieved from http://www.acenet.edu

- Australian education international (2012). Research snapshot . retrieved from

-David William Roffers: The Development of a Model For Implementing The Positive Peer Culture Program in an Inner-city High School ,Xerox University Microfilms , 1975.

- Dennis L. Dolan (1997) Cultural Adjustment of International University Students to American Academic Life: An Interview Study, Ph. D., University of Kansas's "D.A,L" (58),1997.

- Dewey J. Culture and Assertiveness Training, Journal of Behavioral Disorders , V(5),1980.

- Janice H. schoplerMaedag. Galinsky : Conceptualizing Social Work Practice with Group : Encyclopedia of Social work , 19 thed ,( NASW) press , Washing ton, Dc, 1995 , part 2 .

- Jenkins, John \&Galloway, Fred: The Adjustment Problems Faced by International and Overseas Chinese Students Studying in Taiwan Universities : A Comparison of student and faculty staff perceptions (EJ869841), Asia pacific Education Review , v.10 , n.2 , P159,2009.

- kah long chue, and, youyanNie, (2016), International students motivation and learning approach : Acomparison with local students, journal of international students, Vol 6 (3) .

- Karuppan,c.,andbarari,M. (2010) . perceived discrimination al students learning: an empirical investingation . Journal of Higher Education pocy and Management,33(1).

- Klomengah, R.(2006). Social factors relating to alienation experienced by international students in the united states. College student journal, vol 40(2). 